\title{
A Novel Method for Decomposing and Recycling Ammonium Bicarbonate Solutions
}

\author{
Tanita Gettongsong, Mojtaba Taseidifar, Muhammad Shahid and Richard M. Pashley ${ }^{\star}$
}

\author{
School of Physical, Environmental \& Mathematical Sciences, UNSW Canberra, Northcott Drive, Canberra, \\ ACT 2610, Australia
}

\begin{abstract}
A new way of decomposing and recycling ammonium bicarbonate $(A B)$ in aqueous solution has been achieved using a membrane transport process with both dense and porous hollow fibre membranes, which offer efficient heat and mass transfer coefficients. It has been established that the decomposition of $A B$ solutions occurs via contact through a permeable membrane, of $A B$ solutions pre-heated to $80^{\circ} \mathrm{C}$, with a continuous counter-flow of dehumidified air at room temperature. In this process, ammonia $\left(\mathrm{NH}_{3}\right)$ and carbon dioxide $\left(\mathrm{CO}_{2}\right)$ gases permeate through the membrane and are thereby separated from the feed solution and they can then be collected into aqueous solution, for recycling purposes. The new process could, for example, be applied to the treatment of concentrated $A B$ solutions used as draw solutions in forward osmosis (FO) or in the regeneration of depleted ion exchange resins. The results also show that $A B$ recovery depends largely on the membrane surface area. The membrane can be used and optimised to achieve a high decomposition rate for $A B$ with a single pass system to avoid additional pumping of the solution.
\end{abstract}

Keywords: Thermal decomposition, Membrane distillation, Hollow fibre membrane, Ammonium bicarbonate.

\section{INTRODUCTION}

Ammonium bicarbonate $(A B)$ is a thermolytic salt, which is capable of decomposing in aqueous solution at low temperatures. Gokel [1] investigated the decomposition of $A B$ ranging between 35 and $80{ }^{\circ} \mathrm{C}$. The complete decomposition of $A B$ into its individual constituents was observed above $60{ }^{\circ} \mathrm{C}$, which is described by the reaction:

$$
\mathrm{NH}_{4} \mathrm{HCO}_{3(a q)} \stackrel{\Delta}{\rightleftarrows} \mathrm{NH}_{3(g)}+\mathrm{CO}_{2(g)}+\mathrm{H}_{2} \mathrm{O}
$$

Shahid et al., [2] also proposed that the bubble column evaporator (BCE) process could facilitate the thermal decomposition of $A B$ solutions (both dilute and concentrated) at lower solution temperatures (of around $45^{\circ} \mathrm{C}$ ) and at a faster rate.

$A B$ solutions have a wide variety of industrial applications. For instance, they are used as a draw solution in Forward Osmosis (FO) desalination. Therefore, simultaneous separation of $\mathrm{NH}_{3}$ and $\mathrm{CO}_{2}$ gases from an aqueous $\mathrm{NH}_{4} \mathrm{HCO}_{3}$ solution with low energy consumption is a key issue for the commercialisation of $\mathrm{FO}$ desalination $[3,4]$. Also, it has been recently demonstrated by Chandrasekara et al. [5] that $A B$ solutions can be used in the regeneration step for depleted ion exchange resins and this can replace the use of acid and base washing, which is one

"Address correspondence to this author at the School of Physical, Environmental \& Mathematical Sciences, UNSW Canberra, Northcott Drive, Canberra, ACT 2610, Australia; Tel: +612434828298; Fax: +61262688298; E-mqil: r.pashley@adfa.edu.au of the biggest drawbacks with the use of ion exchange resins. Hence, using an $A B$ solution as regenerant can resolve this issue and the decomposition of the product $A B$ solution can provide drinking water for human consumption as well as re-forming the regenerant solution [5].

Traditional membrane separation systems, such as Reverse Osmosis (RO), Microfiltration (MF), Ultrafiltation (UF), Nanofiltration (NF), Electrodialysis (ED), Pervaporation (PV), etc., that have already gained wide acceptance in many different areas, are today completed with new membrane systems. Among them, Membrane Contactor technology probably offers the most powerful tool for inter phase mass transfer based on the principles of phase equilibria and are able to immobilize gas or liquid interfaces at the membrane pores due to the hydrophobic nature of the membrane itself, and to create a large contact area for promoting efficient mass transfer [6].

Membrane transport systems using hollow fibre membranes can also be used as an alternative for solute separation because it has many potential advantages, such as low operating pressure, temperature, ease of process scale-up, fast masstransfer and durability of the membrane, over traditional evaporation or RO technology [7-9]. It is also an effective process for removing organic and heavy metals from aqueous solution [10] and from waste water [11]. These membranes have also been used to treat radioactive waste, where the product could be safely discharged to the environment [12]. 
Hollow fibre membranes also targeted for industrial applications (as opposed to medical ones, e.g., blood oxygenation) are available from a variety of sources, although some are designed for pressure-driven filtration processes rather than concentration-driven mass transfer [13].

In connection to this, Shim et al., [14] studied membrane distillation by using commercial microporous hydrophobic hollow fibre polypropylene (PP) membranes to study the effects of various operating conditions including feed solution temperature, mass flow rate and concentration on gas removal and water recovery efficiencies.

Few studies of the decomposition and regeneration efficiency of the $A B$ solution have been carried out. Therefore, in this paper, membrane transport was investigated using both dense silicone and porous Teflon hollow fibre membranes, to study the effect of decomposition, transfer and recycling of $A B$ from aqueous solutions. The dense silicon membranes are non-porous and allow substances to pass through them via a process of solution and diffusion, so transferring substances from one side to the other. The hollow fibre hydrophobic membranes are strongly hydrophobic (made of Teflon or polypropylene) and have small pores designed to prevent liquid water passing through them. Only water vapour exists in the pores. The high surface area membrane efficiently transfers water vapour and atmospheric gases.

\section{MATERIALS AND METHODS}

\subsection{Materials}

Certified reagent grade (>_ $99 \%$ purity) ammonium bicarbonate $\left(\mathrm{NH}_{4} \mathrm{HCO}_{3}\right)$ was supplied by Sigma-Aldrich and was used without further purification. Aqueous solutions were prepared using deionized water. Polytetrafluoroethylene (PTFE) and polydimethylsiloxane (PDMS) membrane contactors were supplied from Membranium (JSC RM Nanotech) and Perm Select (Med Array Inc), respectively. The peristaltic pump, model: WPX1-P1/8M2-J8-B, was supplied from Welco Co.Ltd. Japan. The inlet $A B$ solutions were pumped in at a rate of $40 \mathrm{~mL} / \mathrm{min}$ in all of these experiments. For the highest area unit $\left(2.1 \mathrm{~m}^{2}\right)$ this corresponds to an average solution residence time of about $5 \mathrm{~min}$.

\subsection{Electrical Conductivity Measurements for $\mathrm{NH}_{4} \mathrm{HCO}_{3}$ Solutions}

Ammonium bicarbonate solutions were prepared at a concentration of $0.03 \mathrm{M}$. Electrical conductivity values of all the solutions were measured using a EUTECH CON 700 Conductivity Bench in a thermostat water bath at $25^{\circ} \mathrm{C}$.

\subsection{Study of the Recovery of $A B$ using Different Membranes in a Single Pass Process}

$0.03 \mathrm{M} \mathrm{NH}_{4} \mathrm{HCO}_{3}$ solutions were heated up to $80{ }^{\circ} \mathrm{C}$ to decompose the solution to ammonium $\left(\mathrm{NH}_{3}\right)$ and carbon dioxide gases $\left(\mathrm{CO}_{2}\right)$ just prior to entry into a membrane separator unit using an electrical gas heater (stainless steel tube wrapped with an electrical tape, Duo -Tape Cat. No. is AWH-051-020, HTS/Amptek Company, Stafford, Texas, USA). The temperature of the inlet solution was continuously controlled and monitored using an AC Variac electrical supply and thermocouple (see Figure 1). The room temperature air intake flow rate was fixed at $25 \mathrm{~L} \cdot \mathrm{min}^{-1}$. The gas phase counter-flow collected ammonia $\left(\mathrm{NH}_{3}\right)$ and carbon dioxide $\left(\mathrm{CO}_{2}\right)$ gases, which were continuously

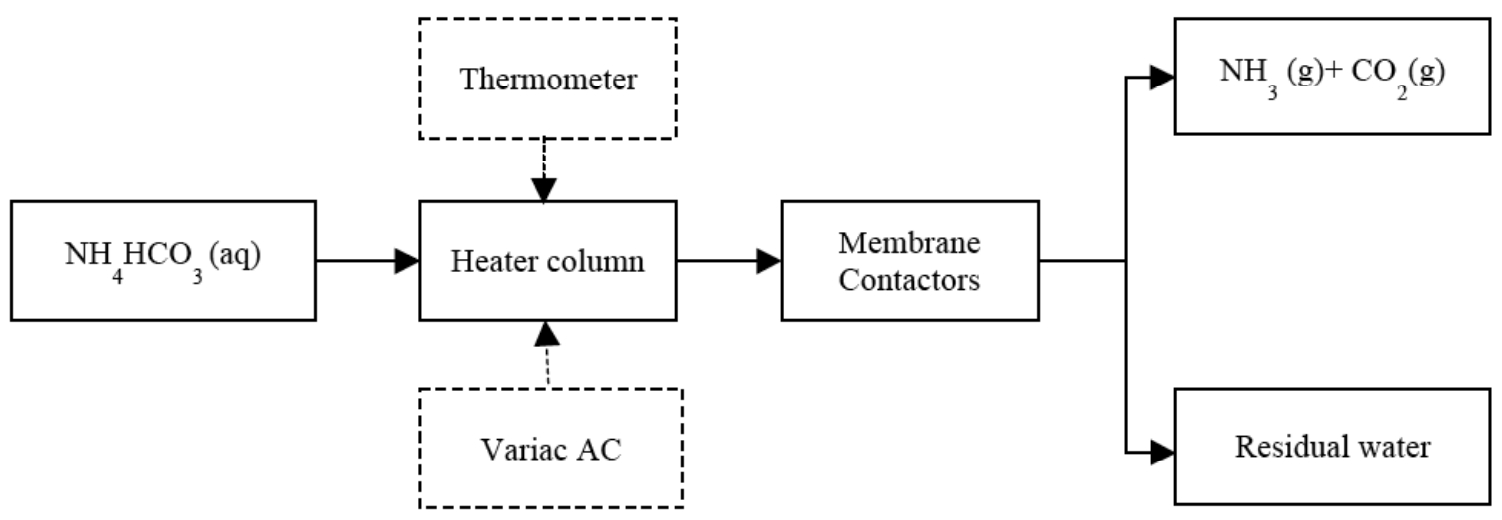

Figure 1: Schematic diagram for the single run system (for all membranes). 
separated through the membrane contactors by a diffusion process. The HF outlet solution was collected and cooled down to room temperature before measuring electrical conductivities using a EUTECH CON 700 Conductivity Bench.

\subsection{Recycling $\mathrm{NH}_{4} \mathrm{HCO}_{3}$ using Multiple Pass Separation with PDMS Membranes}

For the multiple pass recycling system, the same procedure was used as explained above and in Figure 2. After the separation of the decomposed gases, $\mathrm{NH}_{3}$ (g) and $\mathrm{CO}_{2}(\mathrm{~g})$, they were collected via connection to a cool water sample collector. The system was run continuously. During the experiment, the samples were collected to determine their electrical conductivity. The conductivity of the solution was measured every 10 minute throughout the 30 -minute runs. The airflow rate used in these experiments was kept constant at about 50 L. $\mathrm{min}^{-1}$, while the $A B$ solution flow rate was maintained at $50 \mathrm{~mL} \cdot \mathrm{min}^{-1}$. The recycling system is shown schematically in Figure 2 (a), together with experimental details and a photograph in Figure 2 (b).

\subsection{Bubble Column Evaporator (BCE) for Solute Thermal Decomposition}

A vertical glass column with a porous glass sinter (size no 2) at the base (see ref [2]) was used to produce a continuous flow of fine, dry, air bubbles at a flow-rate of $22.5 \mathrm{~L} . \mathrm{min}^{-1}$, pre-heated to $150{ }^{\circ} \mathrm{C}$ into a $0.03 \mathrm{M}$ solution of ammonium bicarbonate. The electrical conductivity of solution samples (cooled and measured at $25{ }^{\circ} \mathrm{C}$ ) was used to monitor the rate of thermal decomposition.
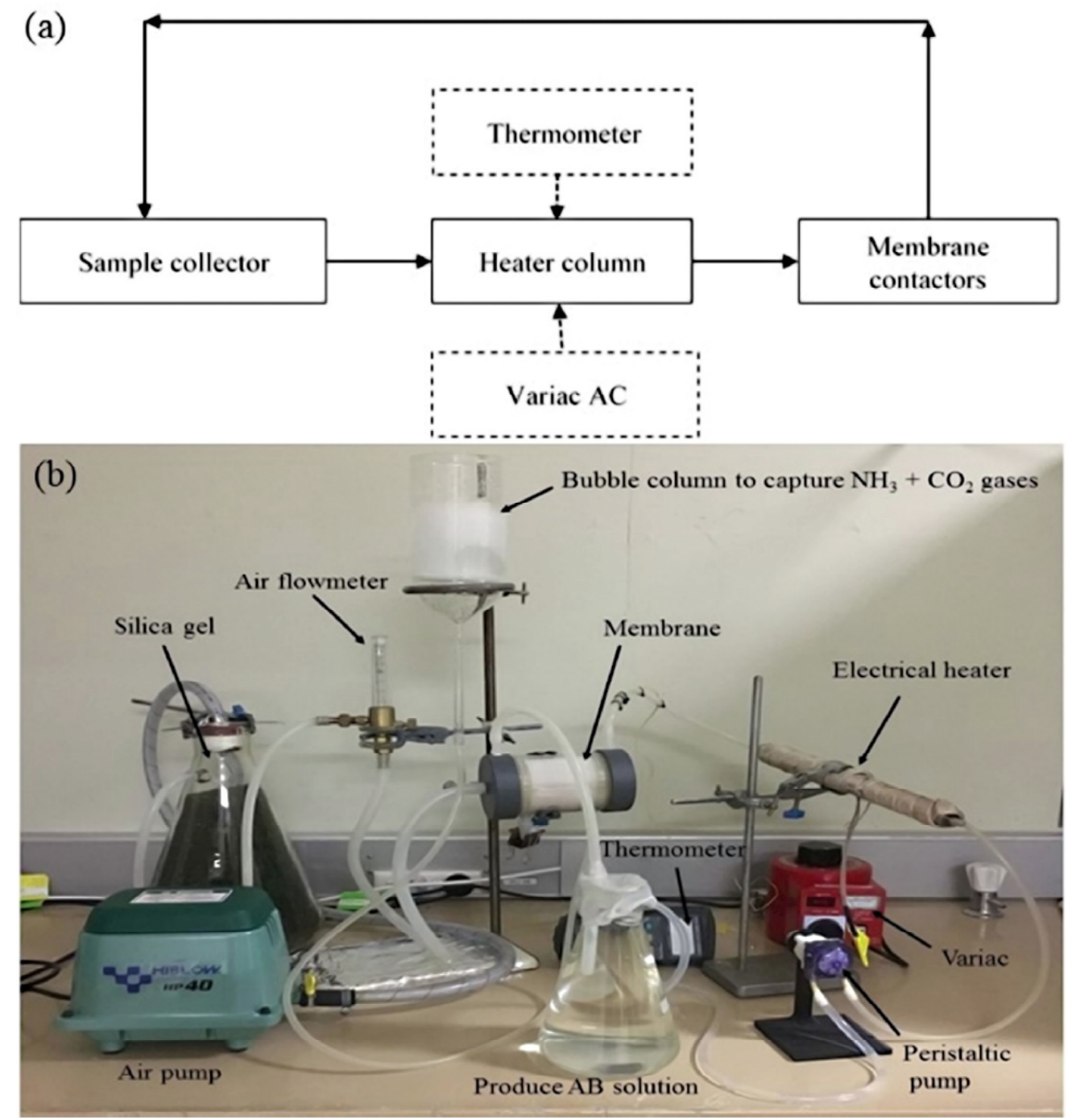

Figure 2: (a) Schematic diagram for the recycling HF system; (b) Photograph of the experimental set up (for a PDMS $\left(2.1 \mathrm{~m}^{2}\right)$ membrane). 


\section{RESULTS AND DISCUSSION}

The thermal decomposition products, of ammonia and carbon dioxide gases, from the pre-heated $A B$ feed solution were passed through the membrane module and then transferred through the walls of the hollow fibre membranes. The gas species were swept out via the membrane walls, shell sides, as permeate and were then recovered in a bubble column containing cold water to restore the $A B$ solution. The results given in Table 1 and Figure 3 show that the PDMS membranes, with $2.1 \mathrm{~m}^{2}$ surface area, showed higher permeability to the gases, with about $57 \%$ AB recovery, whilst PTFE $\left(0.5 \mathrm{~m}^{2}\right.$ surface area) gave a lower $A B$ recovery in the system, of about $14 \%$. However, the recovery rates when scaled by surface area were about the same.

The experimental results obtained in this study indicate that the rate of transport of the decomposed gases, $\mathrm{NH}_{3}$ and $\mathrm{CO}_{2}$, through the $\mathrm{HF}$ membranes depends critically on the surface area of the membrane, rather than the mode of transport through the membrane (i.e. via dense PDMS or porous Teflon membranes). Ammonia is a typical fast permeating compound formed by decomposition of $A B$ solution and shows high permeability values, particularly in the polar polymers, such as PDMS, where substances can pass through the dense membranes by a solution and diffusion process, so transferring substances from one side to the other.

In addition, to measuring the conductivity of the degassed outlet solution to determine recovery rate, the decomposed gases were also collected into cold water and the $\mathrm{pH}$ of these solutions were used to monitor the balance between the acidic and basic gases. Typically a neutral $\mathrm{pH}$ value was observed of about 7.8. This clearly indicates that similar quantities of the two decomposition gases were passed equally through the membrane in this process.

Table 1: $A B$ Recovery with different Membranes with Single Runs with $A B$ Concentration of $0.03 \mathrm{M}$ (Conductivity $=3.23 \mathrm{mS} . \mathrm{cm}^{-1}$ ), Solution Flow Rate $=50 \mathrm{~mL} \cdot \mathrm{min}^{-1}$, Inlet Solution Temperature= $80{ }^{\circ} \mathrm{C}$, Counter-Flow Air Rate $=25$ L. $\min ^{-1}$ and Estimated Solution Residence Times

\begin{tabular}{|c|c|c|}
\hline $\begin{array}{c}\text { Membrane } \\
\text { Type }\end{array}$ & $\begin{array}{c}\text { Conductivity }\left(\mathbf{m S} . \mathrm{cm}^{-1}\right) \\
\text { (Recovery Percentage) }\end{array}$ & $\begin{array}{c}\text { Residence Time } \\
\text { (min) }\end{array}$ \\
\hline \hline PTFE $\left(0.5 \mathrm{~m}^{2}\right)$ & $2.8(13.3 \%)$ & 1.25 \\
\hline PDMS $\left(1 \mathrm{~m}^{2}\right)$ & $2.5(22.6 \%)$ & 2.5 \\
\hline PDMS $\left(2.1 \mathrm{~m}^{2}\right)$ & $1.4(56.6 \%)$ & 5 \\
\hline
\end{tabular}

The efficiency of the single pass membrane degassing process can be estimated in terms of \% recovery rate per min (of residence time) and these values can then be compared with the efficiency of the $B C E$ recovery. Decomposition of $0.03 \mathrm{M} \mathrm{AB}$ solution using the BCE system [2] with an air inlet temperature of $150{ }^{\circ} \mathrm{C}$ was compared with single pass PDMS system with feed of $80{ }^{\circ} \mathrm{C}$ pre-heated $A B$ solutions. The results of the $B C E$ experiments are shown in Figure 4 and show that the BCE method required 15 mins to produce $57 \% A B$ recovery rate; whilst for the PDMS $\left(2.1 \mathrm{~m}^{2}\right)$ module, the required time was only 5 mins (see Table 1). The final steady state solution temperature observed in the BCE experiment was found to be about $41^{\circ} \mathrm{C}$.

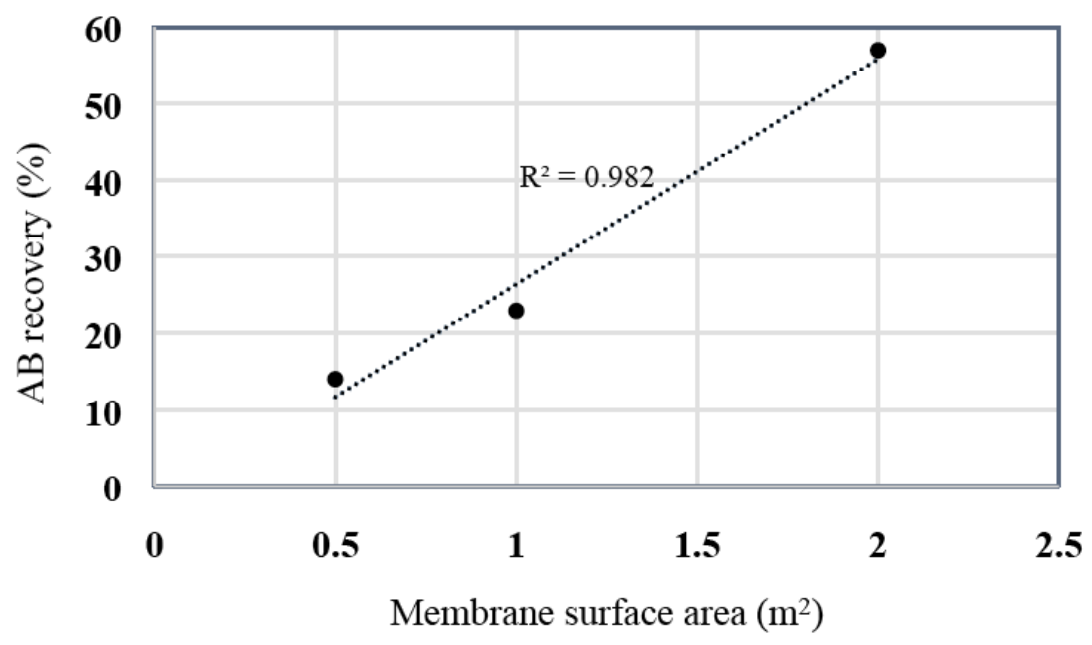

Figure 3: AB recovery percentage vs surface area of HF membranes (PTFE $\left(0.5 \mathrm{~m}^{2}\right)$, PDMS $\left(1 \mathrm{~m}^{2}\right)$ and PDMS $\left(2.1 \mathrm{~m}^{2}\right)$ ). 


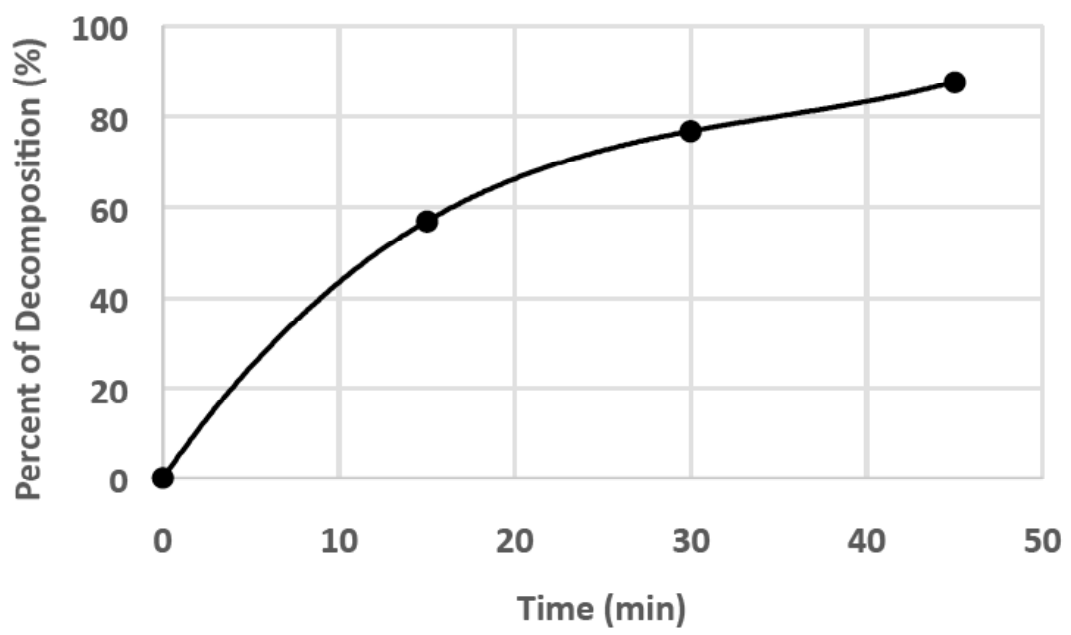

Figure 4: Decomposition percentage of $A B$ solution using a bubble column evaporator (BCE) with an inlet air (at 22.5L.min ${ }^{-1}$ ) temperature of $150^{\circ} \mathrm{C}$ and steady state column solution temperature reaching $41^{\circ} \mathrm{C}$.

As the higher surface area PDMS $\left(2.1 \mathrm{~m}^{2}\right)$ membrane showed higher efficiency in recovering the $A B$ compound, multiple passes of the $A B$ solution were investigated to determine if higher recovery rates were possible with this system (see Figure 2). A peristaltic pump was used to circulate the $A B$ solution which was pre-heated to $80^{\circ} \mathrm{C}$ by an electrical heater just prior to entering the membrane separator unit, on each pass. The results in Table 2 show that running the solution in the system for multiple times leads to higher recapture of the $A B$ compound from the solution, with recovery percentages increased from $57 \%$ to $74 \%$ for the first and third runs, respectively.

These results indicate that at the above flow rate, a silicone membrane of about $4-5 \mathrm{~m}^{2}$ would be required to almost completely remove the decomposed gases from a $0.03 \mathrm{M} A B$ feed solution, in a single pass process. This would increase the residency time of the $A B$ solutions to $10 \mathrm{~min}$, comparing to the residency time of the $2.1 \mathrm{~m}^{2}$ membrane, which was about $5 \mathrm{~min}$.

Table 2: Pre-heated $A B$ Solutions Flowed through PDMS $\left(2.1 \mathrm{~m}^{2}\right)$ Membranes with Multiple Passes, at an Initial AB Concentration of $0.03 \mathrm{M}$ (Conductivity $=3.23 \mathrm{mS} \mathrm{cm}^{-1}$ ), with Solution flow rate of $50 \mathrm{~mL} \cdot \mathrm{min}^{-1}$, Solution Temperature of 80 C (Just Prior to HF Inlet) and with an Air Flow Rate of $25 \mathrm{~L}$. $\mathrm{min}^{-1}$. The Average Residence Time in the HF Unit Was about 5min Per Pass

\begin{tabular}{|c|c|}
\hline Run & Conductivity $\left(\mathrm{mS.cm}^{-1}\right)($ Recovery Percentage) \\
\hline \hline 1st & $1.4(56.6 \%)$ \\
\hline 2nd & $(65.9 \%)$ \\
\hline 3rd & $0.85(73.6 \%)$ \\
\hline
\end{tabular}

\section{CONCLUSIONS}

Porous polytetrafluoroethylene (PTFE) and dense polydimethylsiloxane (PDMS) based hollow fibre membranes can be used to transport thermally decomposed gases from suitable salts via pre-heating the feed solution. The high interfacial area between pre-heated ammonium bicarbonate solutions and a continuous counter-stream of air, within a hollow fibre membrane unit, can produce high heat and mass transfer coefficients, even in single-pass processes. The decomposition efficiency of ammonia $\left(\mathrm{NH}_{3}\right)$ and carbon dioxide gases $\left(\mathrm{CO}_{2}\right)$ could be used commercially for applications in forward osmosis and ion exchange regeneration. The process may also offer many opportunities to facilitate other thermally driven reactions, involving gaseous products, at reduced operating costs.

\section{ACKNOWLEDGEMENTS}

We thank the University of New South Wales, along with The Australian Research Council (ARC grant number DP160100198) for funding this research.

\section{REFERENCES}

1. Gokel GW. Dean's handbook of organic chemistry. 2004, New York: McGraw-Hill.

2. Shahid M, et al. Study of a novel method for the thermolysis of solutes in aqueous solution using a low temperature bubble column evaporator. J Phys Chem B 2015; 119(25): 8072-8079. https://doi.org/10.1021/acs.jpcb.5b02808

3. McCutcheon JR, McGinnis RL, and Elimelech M. A nove ammonia-carbon dioxide forward (direct) osmosis desalination process. Desalination 2005; 174(1): 1-11. https://doi.org/10.1016/j.desal.2004.11.002

4. Cath TY, Childress AE and Elimelech M. Forward osmosis: Principles, applications, and recent developments. Journal of 
Membrane Science 2006; 281(1): 70-87 https://doi.org/10.1016/j.memsci.2006.05.048

5. Chandrasekara NPGN and Pashley RM. Process and System for Desalinating Saline Water 2015: IP Australia. p. 1-19.

6. Curcio E and Drioli E. Membrane Distillation and Related Operations-A Review. Separation \& Purification Reviews 2005; 34(1): 35-86. https://doi.org/10.1081/SPM-200054951

7. Ding Z. et al. Experimental study of ammonia removal from water by membrane distillation (MD): The comparison of three configurations. Journal of Membrane Science 2006; 286(1): 93103.

https://doi.org/10.1016/j.memsci.2006.09.015

8. Lawson $\mathrm{KW}$ and Lloyd DR. Membrane distillation. Journal of Membrane Science 1997; 124(1): 1-25. https://doi.org/10.1016/S0376-7388(96)00236-0

9. Yang $\mathrm{MC}$ and Cussler E. Designing hollow-fiber contactors. AIChE Journal 1986; 32(11): 1910-1916. https://doi.org/10.1002/aic.690321117

10. Garcia-Payo MC, Izquierdo-Gil MA and Fernández-Pineda C. Air gap membrane distillation of aqueous alcohol solutions.
Journal of Membrane Science 2000; 169(1): 61-80. https://doi.org/10.1016/S0376-7388(99)00326-9

11. Zolotarev PP, et al. Treatment of waste water for removing heavy metals by membrane distillation. Journal of Hazardous Materials 1994; 37(1): 77-82. https://doi.org/10.1016/0304-3894(94)85035-6

12. Zakrzewska-Trznadel G, Harasimowicz $M$ and Chmielewski AG. Concentration of radioactive components in liquid low-level radioactive waste by membrane distillation. Journal of Membrane Science 1999; 163(2): 257-264. https://doi.org/10.1016/S0376-7388(99)00171-4

13. Gabelman A and Hwang ST. Hollow fiber membrane contactors Journal of Membrane Science 1999; 159(1): 61-106. https://doi.org/10.1016/S0376-7388(99)00040-X

14. Shim SM, Lee SJ and Kim WS. Experimental study on the performance evaluation of vacuum distillation process for $\mathrm{NH} 4 \mathrm{HCO} 3$ removal. Journal of Mechanical Science and Technology 2013; 27(4): 1171-1178. https://doi.org/10.1007/s12206-013-0304-7

http://dx.doi.org/10.15379/2410-1869.2018.05.02.02

(c) 2018 Gettongsong et al.; Licensee Cosmos Scholars Publishing House.

This is an open access article licensed under the terms of the Creative Commons Attribution Non-Commercial License

(http://creativecommons.org/licenses/by-nc/3.0/), which permits unrestricted, non-commercial use, distribution and reproduction in any medium, provided the work is properly cited. 